\title{
LOS PRIMEROS MOMENTOS DE AUXILIO SOCIAL Y SUS CONSTRUCCIONES PARA LA INFANCIA. LA PRENSA COMO MEDIO DE PROPAGANDA
}

\author{
The early moments of Social Help and its buildings for childhood. \\ The press as a means of propaganda
}

\author{
Cristina GONZÁLEZ MAZA \\ Universidad de Salamanca \\ E-mail: u58836@usal.es
}

Fecha de recepción: 20-01-2010

Fecha de aceptación: 29-01-2010

\begin{abstract}
RESUMEN: El objetivo de este trabajo es el estudio de Auxilio Social, una de las organizaciones asistenciales más importantes y con mayor actividad del pasado reciente de España. Surgió para cubrir las necesidades de una población carente de medios por los efectos devastadores de la guerra. De todas sus construcciones para los más necesitados, un elevado número estaban destinadas al mundo infantil. Para conocer mejor el funcionamiento de esta organización, además de la consulta de algunos trabajos monográficos, el manejo de la prensa local ha resultado de gran ayuda, ya que es un reflejo de la sociedad en la que surge.

Palabras Clave: Auxilio Social/ Arquitectura/ Prensa/ Beneficencia/ Educación/ Infancia
\end{abstract}

ABSTRACT: The aim of this work is the study of Social Help, one of the most important aid organizations and greater activity in the recent past in Spain.

Emerged to meet the needs of a population without means for the devastating effects of war. Of all the buildings for the poor, large numbers were intended for children's world. To better understand the operation of this organization, besides the consultation of some 
monographs, managing the local press has been a great help, since it is a reflection of the society in wich it arises.

Keywords: Social Help, Architecture, Press, Charity, Education, Childhood

\section{LOS ORÍGENES DE AUXILIO SOCIAL}

La organización de carácter asistencial que más importancia adquirió durante el Franquismo fue la de Auxilio Social, que surgió de la conjunción de Mercedes Sanz Bachiller y Javier Martínez de Bedoya en 1936, aunque inicialmente recibió el nombre de Auxilio de Invierno.

Con la llegada del siglo XX se despertó en la sociedad española un creciente interés por la llamada "cuestión social", por solucionar el problema de la ayuda a los más desfavorecidos de la sociedad, problema que se agravó con la Guerra Civil, cuando todos los esfuerzos de la beneficencia tradicional resultaban insuficientes ante la gran masa de población que día a día sufría los estragos de la guerra. Durante la Segunda República, la beneficencia recibió un fuerte impulso con la Constitución de 1931, al considerar al Estado como el "principal proveedor social". El estallido de la Guerra Civil supuso la ralentización del avance de dichas medidas de carácter asistencial, aunque no su completa desaparición. Cabe destacar dos medidas de protección social surgidas tras el conflicto, como el Seguro Obrero de Vejez e Invalidez o SOVI y el Seguro Obligatorio de Enfermedad o SOE, implantados respectivamente en 1939 y 1942. Sin embargo ambas iban dirigidas únicamente a la población trabajadora, por lo que había una gran parte de la población que se quedaba fuera de su área de actuación.

A la hora de referirnos a los orígenes de Auxilio Social hay que hablar, en primer lugar de las dos personas que le dieron forma en el otoño de 1936, Mercedes Sanz Bachiller y Javier Martínez de Bedoya. Mercedes Sanz Bachiller estuvo unida al mundo de la política desde edad temprana, al conocer a Onésimo Redondo en Valladolid en 1929, con el que contrajo matrimonio en febrero de 1931. Onésimo fundó en junio de ese mismo año una revista llamada Libertad, concebida como un vehículo de transmisión de su pensamiento político, que en agosto adquirió forma con la creación de las JCAH (Juntas Castellanas de Actuación Hispánica). En octubre dicha organización se fusionó con la que lideraba Ramiro Ledesma Ramos, dando como resultado la aparición de las JONS (Juntas de Ofensiva Nacional Sindicalista). A comienzos de 1934 Ramiro Ledesma veía como los afiliados a Falange Española, el partido de José Antonio Primo de Rivera, eran cada vez más numerosos, y los sectores financieros se decantaban por este último en detrimento de las JONS. Estos hechos fueron definitivos para que se produjera la fusión de ambos partidos en febrero de 1934, dando lugar a Falange Española de las JONS. 
Javier Martínez de Bedoya conoció a Onésimo a comienzos de los años treinta, mientras estudiaba Derecho en la Universidad de Valladolid, estableciéndose entre ambos una relación de amistad que llevó a Javier a colaborar en la redacción de la revista Libertad y a participar en el partido jonsista en Madrid. Tras la fusión de la organización de Onésimo y Ramiro con Falange Española se produjo una escisión en el partido ${ }^{2}$, que abandonaron aquellos que no estaban de acuerdo con la actuación de Primo de Rivera, como el propio Ramiro Ledesma y, con él, Martínez de Bedoya, que aprovechó la ocasión para viajar a Alemania, en julio de 1935, para continuar sus estudios de Derecho. Allí trabajó durante casi un año como profesor de español, y de la organización benéfica alemana llamada Winterhilfe tomó el modelo para la institución española que fundó al año siguiente en compañía de Mercedes Sanz Bachiller.

Cuando terminó el curso académico en Heidelberg en junio de 1936, volvió a España, encontrándose con un ambiente sociopolítico claramente enrarecido; se avecinaba una guerra. El veinticuatro de julio de 1936, esto es, a los pocos días del alzamiento militar, murió Onésimo Redondo y su hermano Andrés le planteó entonces a Martínez de Bedoya la organización de los sindicatos de la provincia de Valladolid. Eran los momentos iniciales del conflicto y, tras su vuelta de Alemania, se encontraba en la casa familiar de Guernica, donde el alzamiento militar no había prosperado. Con grandes dificultades consiguió llegar a Valladolid, donde volvió a colaborar en Libertad y se encontró con la viuda de su amigo Onésimo. En aquellos momentos Mercedes se ocupaba de la jefatura provincial de la Sección Femenina de Valladolid. José Antonio Primo de Rivera había fundado dicha institución en junio de 1934 dentro de Falange Española, para acoger en ella a las mujeres de Falange. Además, había nombrado a su hermana Pilar jefe nacional de la organización. Aunque inicialmente se creó para asistir a los presos del partido, con el estallido de la guerra tuvieron que dedicarse a las labores de enfermería y de asistencia a las víctimas del conflicto.

Tras el encuentro que mantuvieron Mercedes y Javier, ambos comprendieron la necesidad de crear un sistema asistencial que realmente funcionara. Acababa de comenzar una guerra que duraría varios años y los afectados por ella serían numerosos por lo que era necesario crear una institución que partiera de planteamientos nuevos, diferentes de los que inspiraron la beneficencia tradicional. Así nació el Auxilio de Invierno, posteriormente Auxilio Social.

Durante su estancia en Heidelberg, a Javier le había llamado la atención una asociación alemana de carácter asistencial y que llevaba por nombre Winterhilfe (Auxilio de Invierno). Esta asociación sólo funcionaba en invierno, de ahí su nombre, y tenía como finalidad recoger donativos en la calle, entregando pequeñas insignias a los donantes, para, con el dinero recogido, 
comprar ropa de abrigo y alimentos a los más necesitados. De su reunión con Mercedes nació el proyecto del Auxilio de Invierno, tomando el nombre y el carácter eventual de la organización alemana3. En octubre de 1936 comenzó a tomar forma el proyecto de ambos en un Valladolid que ya empezaba a sentir las consecuencias de la guerra, y el día treinta de ese mismo mes se abrió en la ciudad el primer comedor infantil. La intención de ambos era que el proyecto se convirtiera en una organización de carácter permanente y que se extendiera al resto de España, algo que fueron consiguiendo poco a poco. Al año de su funcionamiento ya contaban con más de setecientos comedores, cerca de dos mil quinientos al final de la guerra ${ }^{4}$.

A lo largo de 1937 Auxilio de Invierno fue creciendo y ganando un peso cada vez mayor en el panorama de la beneficencia española, garantizando así su permanencia. El catorce de enero pasó a depender del mando falangista, y ya en febrero se autorizaron sus cuestaciones, aunque, sin duda el paso más claro hacia su independencia de la Sección Femenina de Pilar Primo de Rivera llegó tras la unificación de los partidos FE de las JONS y Comunión Tradicionalista en uno solo, FET-JONS. Tras una reunión en Salamanca de los líderes de Auxilio de Invierno con Serrano Súñer y el militar López Bassa, éste creyó que, después de la creación del partido único, era necesario darle una mayor autonomía y carácter de permanencia a dicha organización, y por ello, en mayo de ese mismo año, convirtió Auxilio de Invierno en la Delegación Nacional de Auxilio Social, nombrando a Martínez de Bedoya secretario y a Sanz Bachiller delegado nacional ${ }^{5}$. En febrero de 1938 recibió otro fuerte impulso, al ser nombrado Martínez de Bedoya Jefe del Servicio Nacional de Beneficencia, con lo que Auxilio Social comenzó a recibir más privilegios al ocupar uno de sus fundadores un puesto elevado en la beneficencia a nivel nacional.

Casi desde sus comienzos, en 1937, nació la Asesoría Técnica Nacional, que a su vez estaba dividida en varias asesorías. Las integraban personas especializadas en diferentes materias, y se encargaban de todos los aspectos concernientes a las mismas. De los nuevos centros que abría Auxilio Social, ya fueran de nueva planta o una adaptación de edificios preexistentes, se encargaba la Asesoría Técnica de Arquitectura, de la que formaba parte el arquitecto Eduardo Lozano Lardet ${ }^{6}$.

Por lo que se refiere a la financiación de esta nueva organización, reconocida ya por el Estado, la ayuda llegaba de cualquier parte del territorio español, a través de las donaciones, las postulaciones y la Ficha Azul'; pero también del extranjero, gracias a la colaboración de Auxilio Social con otras organizaciones extranjeras como Ayuda Suiza ${ }^{8}$. Además Sanz Bachiller creó una nueva agrupación conocida como los "Amigos de Auxilio Social", estableciendo comités en diferentes capitales europeas, en las que se celebraban fiestas be- 
néficas y reuniones para recaudar fondos que llegaban a España, y que Auxilio Social se encargaba de administrar entre sus diferentes establecimientos.

La Delegación Nacional de Auxilio Social experimentó fuertes cambios en la etapa final de la guerra y los años iniciales del nuevo régimen. Mientras la Iglesia adquiría un peso cada vez mayor en la organización, se producían cambios en el personal que ocupaba los puestos de poder en la misma. El más importante de estos cambios fue la dimisión de Mercedes Sanz Bachiller como delegada nacional'. La disolución de esta organización llegó con el final del Régimen franquista, en 1975.

\section{LAs CONSTRucciones de Auxilio Social a través DE LA PRENSA}

Como ya se ha comentado, aunque Auxilio Social nació inicialmente con carácter temporal, para ayudar a las víctimas de una guerra que se presentaba larga, consiguió establecerse de manera permanente tras el conflicto, al principio de una posguerra aún más larga. Los servicios que prestaba iban destinados a cumplir las necesidades más básicas del ser humano, la de alimento, a través de los comedores y cocinas de hermandad ${ }^{10}$, y la de un lugar donde cobijarse, con los hogares infantiles.

Desde sus inicios, un aspecto al que Auxilio Social prestó gran atención fue la propaganda de la organización. A parte de los medios propagandísticos más frecuentes, como los carteles, los folletos, o las consignas para que fueran radiadas, la Oficina Central de Propaganda potenció al máximo el impacto visual de la fotografía. En muchas ocasiones la prensa fue el medio preferido para difundir estas instantáneas del personal de la organización repartiendo comida entre los habitantes de una localidad recién tomada por los sublevados, aunque no fue el único ${ }^{11}$. Su intención era transmitir la eficacia de Auxilio Social y mostrarse como una institución nueva y diferente del sistema benéfico tradicional. Por ello el uso de la prensa como vehículo trasmisor de las actividades de la organización fue primordial.

Por un lado estaban los artículos referentes a las inauguraciones de los nuevos edificios de la organización. En ellos el periodista relataba, con todo detalle, el desarrollo de las celebraciones, así como una lista de todas las personalidades asistentes al evento, incluyendo en algunas ocasiones fragmentos de los discursos inaugurales. Había otro tipo de reportajes que se publicaban ocasionalmente sobre un determinado edificio o sobre un servicio de la organización en particular. En este caso el periodista se trasladaba al establecimiento en cuestión para conocer en detalle el funcionamiento del mismo, su distribución, las diferentes estancias, el número de asistidos, etc. Así mismo era frecuente la publicación, cada cierto tiempo, de entrevistas con las auto- 
ridades de Auxilio Social, en las que se hablaba de lo que había conseguido la organización en los últimos tiempos, los proyectos para el futuro o el presupuesto del que disponían para su realización. El objetivo era conseguir financiación para seguir adelante, demostrando lo positivo de su labor, su eficacia y que su presencia era necesaria en la sociedad del momento.

Una de las principales preocupaciones de Auxilio Social fue disminuir el índice de mortalidad infantil, que por aquellas fechas era muy elevado. A causa de la guerra muchas mujeres habían perdido a sus maridos, el trabajo, y los niños se habían quedado huérfanos, estaban enfermos, vivían en la calle y se veían obligados a mendigar para sobrevivir. Para combatir esto creó, en 1937, la Obra de Protección a la Madre y al Niño, dirigida a atender a los dos sectores de la sociedad que resultaban más perjudicados con el conflicto: las mujeres embarazadas y la infancia. En los establecimientos de la Obra, además de darles una formación a los asistidos ${ }^{12}$, hacían un seguimiento de sus hábitos de vida, dotando a todos los centros de salas médicas, dándole además una gran importancia a la formación religiosa, por lo que una constante en todos los establecimientos fue la capilla.

Las mujeres recibían ayuda en centros como los hogares de embarazadas o las colonias de recuperación. En este tipo de lugares se les facilitaba el alojamiento a las mujeres con pocos recursos económicos, estando cercano el momento de dar a luz, y a aquellas que, siendo madres, pasaran por un período de cansancio físico y necesitaran recuperarse. En las colonias, además, se les impartía unos principios de puericultura y una educación enfocada a la obtención de un trabajo, para que, al salir del centro, pudieran tener un sueldo con el que mantener a sus hijos, criándolos en un ambiente con las condiciones higiénicas adecuadas para el buen desarrollo de los niños.

Para la infancia se abrieron multitud de centros a los que asistían tanto niños huérfanos como aquellos que procedían de familias con pocos recursos económicos. Había varios tipos de establecimientos en función de la edad de sus residentes. Para los más pequeños se habilitaron los centros de alimentación infantil, en los que se daba comida a niños que no podían tener más de dos años, y las guarderías y los jardines maternales, que ya incluían cierto carácter educativo en sus actividades. Los niños entre los tres y los siete años iban a los hogares infantiles mientras que, a partir de los siete y hasta los doce, asistían a los llamados hogares escolares. Una vez que el niño llegaba a la edad de trece años podía asistir a los hogares de aprendices, más especializados en darle una educación enfocada a la formación en un determinado oficio para que pudiera acceder a un trabajo en la vida adulta. Junto a estos hogares, con un carácter más formativo se establecieron las colonias infantiles, situadas preferentemente en zonas montañosas o de playa, destinadas a niños enfermos o que necesitaran reposo, y a las que solían asistir en los meses de verano. 
En el caso salmantino, los edificios construidos por esta obra asistencial en la provincia siguieron las mismas tipologías que en otras localidades españolas. Auxilio Social construyó multitud de edificios dentro de esta Obra de Protección a la Madre y al Niño, aunque en muchos casos no eran construcciones de nueva planta, sino adaptaciones de locales ya existentes. Este fue el caso de un Hogar-Cuna que abrió sus puertas en 1940. La Caja de Ahorros de Salamanca había puesto a disposición de Auxilio Social un Preventorio-Escuela, que ésta adaptó, convirtiéndolo en un nuevo establecimiento para la infancia. Con motivo de la apertura de este nuevo centro en la capital, El Adelanto publicó el doce de octubre un reportaje sobre el mismo, incluyendo una entrevista con el presidente de la Diputación Provincial y con el Delegado Provincial de Auxilio Social ${ }^{13}$. Ambos consideraban el problema de la beneficencia como un "mal endémico" que la nueva organización asistencial venía a paliar. Por una parte, hacían referencia a los últimos proyectos realizados, como una Policlínica con la que querían llevar a cabo un "control sanitario, social y moral" de los asistidos, y por otra, avanzaban algunos de los proyectos futuros, entre ellos un Hogar Infantil y una Maternidad con la finalidad de "controlar a la madre antes de traer al mundo el presunto hijo". La educación que querían dar a los niños que asistían a estos centros estaba fundamentada en los principios del "Catolicismo practicante", pensamiento acorde con el peso que la religión estaba ganando en la organización asistencial. Todas estas afirmaciones estaban en consonancia con el interés de la Obra de Protección a la Madre y al Niño, de disminuir la mortalidad infantil, realizando un seguimiento de los niños desde que estaban en el vientre materno.

El cinco de noviembre del mismo año, tanto El Adelanto como $L a G a$ ceta Regional publicaron un nuevo artículo sobre el Hogar-Cuna, describiendo con todo lujo de detalles sus instalaciones, sin escatimar elogios para con la organización ${ }^{14}$. Completaban el reportaje cinco fotografías del centro en las que aparecían las trabajadoras haciéndose cargo de los niños. De nuevo el periodista afirmaba que con este nuevo centro se conseguía "disminuir considerablemente la mortalidad", algo primordial para Auxilio Social.

En relación a la afirmación de la crisis de la beneficencia, a principios de 1941, El Adelanto publicó un artículo que hacía balance de las cuentas y los presupuestos de la Diputación provincial, y daba por solucionado el problema de la beneficencia ${ }^{15}$. El periodista consideraba necesario "terminar con el bochornoso espectáculo de unos servicios instalados deficientemente como los del Hospicio, Casa-Cuna, Casa de Maternidad, Manicomio y Asilo de Incurables de Ciudad Rodrigo". Por ello, el Estado tenía ya en su poder los planos de los nuevos edificios proyectados y los estaba estudiando. Además Auxilio Social y la Diputación provincial se habían hermanado, consiguiendo entre ambas la apertura del Hogar-Cuna ya mencionado. 
Para Auxilio Social uno de los momentos de mayor importancia eran las inauguraciones de los nuevos establecimientos, por lo que destaca el elevado número de crónicas inaugurales en la prensa del momento. Era el mejor sistema de propaganda, pues demostraban que sus proyectos se materializaban. Este tipo de celebraciones solían desarrollarse casi siempre del mismo modo. En primer lugar, llegaban las autoridades invitadas al evento, entre las que no podían faltar el Gobernador civil ni la representación de las jerarquías eclesiástica y militar. Tras la bendición de los locales por parte de un cura, los asistentes visitaban las instalaciones y, posteriormente, llegaba el momento de los discursos de rigor de dichas personalidades. Finalmente se ponía en funcionamiento el local, en el caso de los comedores repartiendo la primera comida a los niños y, a veces, también prendas de ropa. Estos actos eran una constante en todas las inauguraciones, aunque su orden podía variar. Como muestra destaca el artículo que publicó La Gaceta Regional, el veinte de abril de 1945, sobre la inauguración de la Casa de la Madre ${ }^{16}$. Este artículo relata en detalle el desarrollo de las celebraciones que habían tenido lugar el día anterior, comenzando con un listado de las autoridades invitadas al evento, entre ellas el obispo de la diócesis y el director general de beneficencia. El diecinueve, día de la apertura, publicó un reportaje que incluía dos fotografías de las instalaciones y una descripción minuciosa ${ }^{17}$. Igualmente, El Adelanto publicaba el día de la inauguración un reportaje sobre el nuevo edificio $^{18}$, haciendo, en la primera parte del artículo, un recordatorio de los más destacados establecimientos de Salamanca abiertos por Auxilio Social en los últimos tiempos. La nueva Casa de la Madre estaba enclavada cerca de la Alamedilla, pues era frecuente situar este tipo de instituciones en lugares relativamente apartados del centro. La organización había conseguido convertir un "caserón descuidado" en un "verdadero sanatorio", por lo que estaba cumpliendo una "grande y sublime misión", justificando así su existencia.

La mayor parte de las instituciones abiertas por Auxilio Social eran comedores y cocinas de hermandad, pues la necesidad más básica de la población era la de alimento. Auxilio Social nombraba a delegados para que se encargaran de buscar los almacenes en los que guardar los víveres, hasta que pudieran instalar el comedor en un local adecuado. Estos delegados se encargaban igualmente de buscar a jóvenes para trabajar en estos centros ${ }^{19}$. Durante la guerra y poco tiempo después de su fin, la distribución de los alimentos tenía que ser rápida, por lo que muchos de los comedores abiertos en estos momentos no eran construcciones de nueva planta, sino adaptaciones de edificios previos. Un ejemplo es el comedor que se abrió en Macotera el veinticuatro de noviembre de 1940. Dos días después, El Adelanto publicó la crónica de la inauguración ${ }^{20}$. Este nuevo comedor estaba situado en el antiguo teatro de la localidad, y tras ser bendecido comenzó a funcionar, sirviéndose la primera comida a los niños. 
Con el paso de los años, Auxilio Social fue relajando su labor. La urgencia de los momentos iniciales fue despareciendo. Al comienzo del conflicto era necesario actuar con rapidez y acondicionar un local cualquiera para empezar con el reparto de alimentos cuanto antes. Cuando esta necesidad de comida estaba cubierta, llegaba el momento de construir nuevos centros, para acoger en ellos a los afectados por la guerra, proporcionándoles un techo. El elevado número de establecimientos que Auxilio Social abrió por toda España, y la continuidad de la organización, casi hasta nuestros días ponen de manifiesto la importante labor que realizó en uno de los momentos más difíciles de la historia de este país.

\section{NOTAS}

${ }^{1}$ CENARRO, A.: La sonrisa de Falange. Auxilio Social en la guerra civily en la posguerra. Crítica. Barcelona, 2006, pág. XII.

${ }^{2}$ Acerca del pensamiento político de Martínez de Bedoya vid. ORDUÑA PRADA, M.: El Auxilio Social (1936-1940). La etapa fundacionaly los primeros años. Escuela Libre Editorial. Madrid, 1996.

${ }^{3}$ En los momentos iniciales contaron con la ayuda de Kroeger, el adjunto del embajador alemán Von Faupel, para adaptar el modelo alemán a España.

${ }^{4}$ PENELLA, M.: "Mercedes Sanz Bachiller, viuda de Onésimo Redondo y creadora del Auxilio de Invierno". ABC (Madrid), 13-10-2007, pág. 60. Manuel Penella defiende en esta necrológica la organización creada por Mercedes Sanz y Javier Martínez, como algo más que una mera copia de la Winterhilfe nazi.

${ }^{5}$ CENARRO, A.: Op. cit., pág. 8. Se autorizaba, además, a esta Delegación Nacional de Auxilio Social a unificar todas las obras benéficas surgidas tras el alzamiento militar del dieciocho de julio y las que financiaba el Fondo de Protección Benéfico Social.

${ }^{6}$ Sobre las diferentes asesorías y su funcionamiento vid. ORDUÑA PRADA, M.: Op. cit., pág. 141.

${ }^{7}$ CENARRO, A.: Op. cit., págs. 46-50. Las dos últimas eran de carácter obligatorio; sin embargo, en el caso de las donaciones, la frecuente aparición de largas listas en la prensa con los nombres y apellidos de los donantes así como las cantidades que daban a Auxilio Social, las convertía casi en un deber que todos los ciudadanos debían cumplir.

${ }^{8}$ Ibídem: Págs. 29-37. Junto a la Ayuda Suiza fue relevante la presencia de los cuáqueros actuando en España, en colaboración con Auxilio Social. Sin embargo su trabajo se volvió más difícil tras el final de la guerra, al comprender que no podían ejercer con libertad su labor humanitaria y ver la dureza con que eran tratados los refugiados de los territorios recién ocupados 
${ }^{9}$ Ibidem: Págs. 63-65. Ante la pérdida de autonomía de la organización por la que tanto había luchado, y con varios problemas de fondo sobre irregularidades en el funcionamiento de la delegación, Mercedes Sanz Bachiller acabó presentando su dimisión el doce de enero de 1940.

${ }^{10}$ ORDUÑA PRADA, M.: Op. cit., págs. 307-316. Con la terminación de un edificio o simplemente su adaptación a los nuevos fines de Auxilio Social llegaba la gran fiesta de su inauguración, de la que se daba cuenta con todo lujo de detalles en la prensa. Estos actos inaugurales, a los que asistían todas las autoridades locales, formaban parte del sistema propagandístico.

${ }^{11}$ CENARRO, A.: Op. cit., págs. 20-22. La eficacia de las fotografías fue tal que incluso crearon su propio Servicio Fotográfico, que pronto dio resultados, como la publicación de un libro de fotografías titulado "Auxilio Social".

${ }^{12}$ ORDUNA PRADA, M.: Op. cit., págs. 327-352. A pesar de los esfuerzos de Auxilio Social de configurarse en una institución benéfica diferente al modelo tradicional, intentando imprimir en sus obras un factor "más humanitario", no aceptaba en sus centros a una parte de la población, realmente necesitada dentro de los necesitados. Eran las personas con enfermedades infecciosas, que no podían recibir ayuda en los establecimientos de la Obra, para evitar el problema de los contagios.

13 "El Hogar-Cuna y la solución del problema de la Beneficencia". El Adelanto (Salamanca), 12-10-1940, págs. 1 y 3.

14 “El Hogar-Cuna de Auxilio Social”. El Adelanto (Salamanca), 5-11-1940, págs. 4 y 5 y “El Hogar-Cuna es una institución digna de todo encomio”. La Gaceta Regional (Salamanca), 5-11-1940, pág. 8.

15 "La Diputación provincial tiene resuelto el problema de la Beneficencia". El Adelanto (Salamanca), 1-1-1941, pág. 6.

16 “Ayer fue inaugurada la Casa de la Madre”. La Gaceta Regional (Salamanca), 20-41945, pág. 1.

17 “Auxilio Social inaugurará hoy la Casa de la Madre”. La Gaceta Regional (Salamanca), 19-41945, pág. 4.

18 "El Director General de Beneficencia y Delegado Nacional de Auxilio Social, inaugurará hoy, en Salamanca, la Casa de la Madre”. El Adelanto (Salamanca), 19-4-1945, págs. 1 y 4.

${ }^{19}$ CENARrO, A.: Op. cit., págs. 18-19.

20 "Auxilio Social inaugura un comedor en la villa de Macotera". El Adelanto (Salamanca), 26-11-1940, pág. 8. 